\title{
Migratory Pattern of the Spotted Scat (Scatophagus argus) in the Mangrove Estuary of the Matang Mangrove Forest Reserve, Malaysia, Estimated by Stable Isotope Analysis
}

\author{
Shinsuke MORIOKA ${ }^{1 *}$, Katsuhisa TANAKA ${ }^{2}$, Tatsuya YURIMOTO ${ }^{3}$, \\ Faizul M. KASSIM ${ }^{4}$ and Kazumaro OKAMURA ${ }^{3}$ \\ ${ }^{1}$ Fisheries Division, Japan International Research Center for Agricultural Sciences, Tsukuba, Japan \\ ${ }^{2}$ National Research Institute of Far Seas Fisheries, Japan Fisheries Research and Education Agency, \\ Shizuoka, Japan \\ ${ }^{3}$ Seikai National Fisheries Research Institute, Japan Fisheries Research and Education Agency, \\ Taira, Japan \\ ${ }^{4}$ Penang Office of JIRCAS, Batu Maung, Penang, Malaysia
}

\begin{abstract}
Stable isotope ratios of carbon $\left(\delta^{13} \mathrm{C}\right)$ and nitrogen $\left(\delta^{15} \mathrm{~N}\right)$ were determined for the spotted scat (Scatophagus argus) in the Matang Mangrove Forest Reserve in Peninsular Malaysia. The ratios from fish samples along with those obtained from samples of their potential food items (i.e., mangrove leaves in the estuary, coastal phytoplankton, microphytobenthos) revealed wide variations, indicating that $S$. argus utilizes various food items between the coastal area at the river mouth to the inner mangrove estuary. The carbon isotope ratio in the fish body tended to be lower in fish sampled from the inner estuary as compared with fish at the river mouth. The carbon isotope ratio values of the fish body were relatively high in small fish $(<20 \mathrm{~mm}$ in total length [TL]) but lower in fish of 20-100 mm $\mathrm{TL}$, and relatively higher in fish $>100 \mathrm{~mm}$ TL. These findings strongly suggest that small-sized $S$. argus $(<20 \mathrm{~mm} \mathrm{TL})$ migrate from the outer coastal area into the mangrove estuary and utilize the mangrove estuary habitat as their nursery grounds before eventually returning to the river-mouth area as their growth progresses.
\end{abstract}

Discipline: Fisheries

Additional key words: stable carbon/nitrogen isotope ratios, mangrove estuary, fish nursery ground, migration

\section{Introduction}

The Matang Mangrove Forest Reserve (MMFR) on the west coast of Peninsular Malaysia is one of the world's best-managed mangrove forests. The mangrove estuary there supports a variety of fishes (at least 94 species of 37 families) (Hui 2009). Many euryhaline fishes are reported to spawn offshore of the MMFR, and the developing larvae and juveniles move or are carried by tidal currents to inshore areas or estuarine waters in the mangrove forest area (Blaber 2007, Gillanders et al. 2003, Sarpedonti \& Chong 2008, Yamamoto et al. 2010). Among the diverse fish species occurring in the MMFR, the spotted scat (Scatophagus argus) (Perciformes:
Scatophagidae) is highly biomass-dominant (Hui 2009), indicating its prominence in the ichthyofauna composition of the area. The species is an important food fish resource and ornamental aquarium species throughout Southeast Asia (Gupta 2016, Musikasung et al. 2006), including the areas surrounding the MMFR. However, limited information is available on its biological aspects, particularly its migratory pattern relative to growth in the area, including its probable dependency on the mangrove estuary as its feeding and nursery grounds. Data on the species' dynamics in the mangrove estuary could thus be helpful for conservation and management of the $S$. argus resource.

Stable isotope analysis of carbon and nitrogen can 
provide useful information on the origin and migration paths of an organism if the isotopic compositions of its prey differ following the organism's movements to a new habitat (Hobson 1999, Tanaka et al. 2011). More specifically, isotope characterization in fish can help to identify long-term migrant individuals from recent ones by using the isotopic ratios of prey species, since the ratio should reflect the isotopic composition of food assimilated over several weeks to months (Herzka 2005). Hence, stable-isotope data can be compared to distinguish between recent immigrants and individuals that have inhabited the sampling site for a relatively long period (Maruyama et al. 2001, Suzuki et al. 2008).

Given the context above, we thus attempted to estimate the migratory pattern of Scatophagus argus in the mangrove estuary of the MMFR by analyzing its dependence on the food sources provided in the mangrove habitat by means of stable isotope ratios of carbon and nitrogen of the fish body and several potential food items.

\section{Materials and methods}

\section{Study area and sample collection sites}

The Matang Mangrove Forest Reserve (MMFR) (Fig. 1) is the largest single tract of mangrove forest in Malaysia $(40,151 \mathrm{ha})$; it is situated on the northwestern coast of Peninsular Malaysia and measures approximately $52 \mathrm{~km}$ in length and $13 \mathrm{~km}$ in width. The MMFR is a riverine forest-type mangrove that is inundated during most spring high tides, while the water is mainly confined to channels during neap tides. Figure 1 shows the sample collection sites in the northern part of the MMFR. The depth of the Sangga Besar River basin ranges from 4-6 m (between sites R2 and R6), while the coastal and mudflat areas (at site R1) are shallower (1-3 m deep). The site along the Selinsing River (S1) had a depth of 4-5 m, while the sites in the upstream creek areas (C1-C4) had depths of 2-3 m. Mean water temperature in the study area was $29.6^{\circ} \mathrm{C}$ (range $26.6-31 \cdot 1^{\circ} \mathrm{C}$ ). Mean salinity $( \pm$ standard

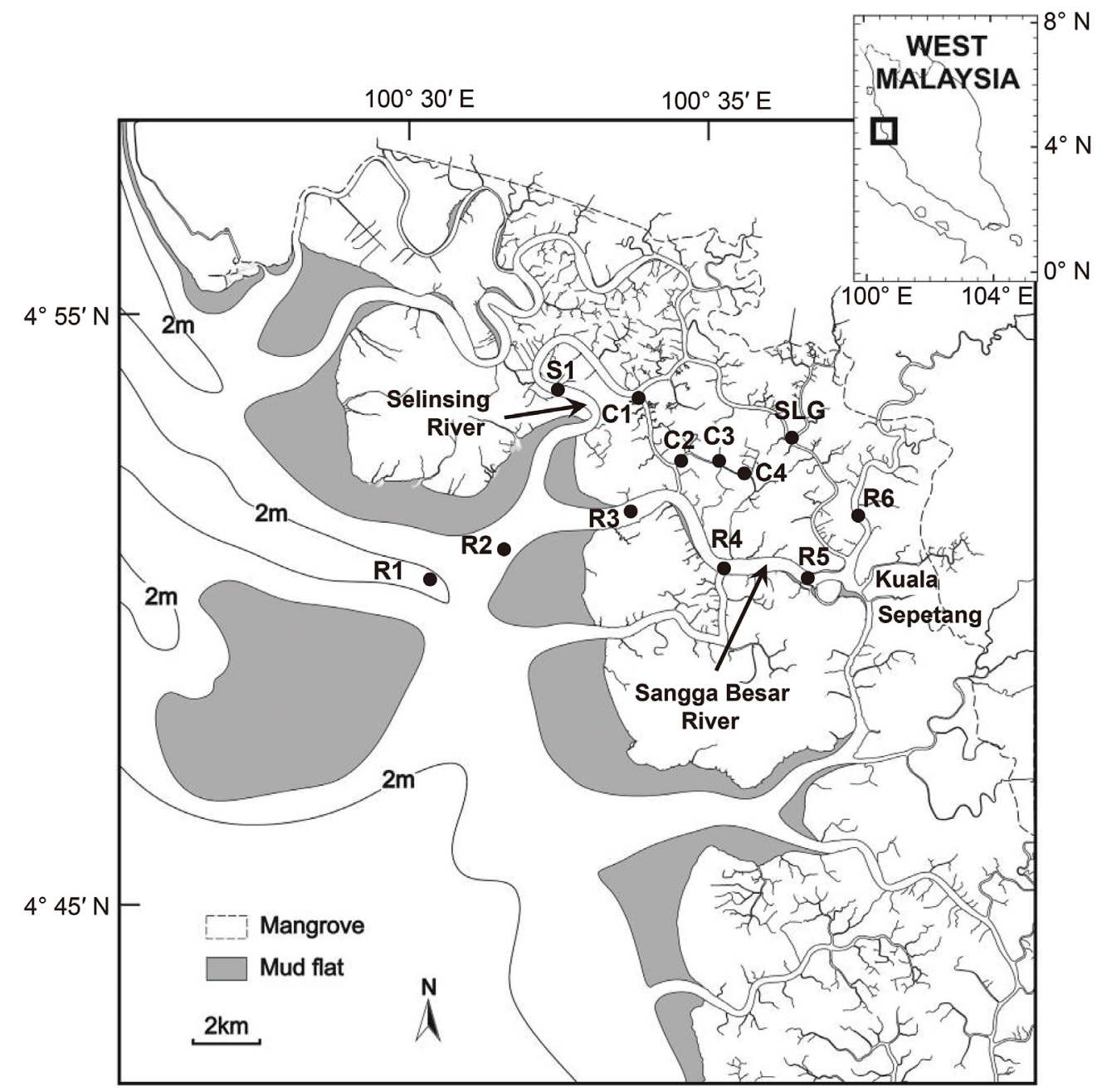

Fig. 1. Sample collection sites for the spotted scat (Scatophagus argus) in the MMFR, Malaysia Letters and numbers denote the codes for each sampling site. 
deviation) of the bottom water was high as $24.5 \pm 1.89 \mathrm{ppt}$ in the outer coastal area (R1), and low as $18.2 \pm 7.4 \mathrm{ppt}$ (R5), $22.5 \pm 2.1 \mathrm{ppt}(\mathrm{S} 1)$ and $20.2 \pm 2.8 \mathrm{ppt}(\mathrm{C} 4)$ in the inner estuary area (Okamura et al. 2010) (Fig. 1). Fish were caught using a 2-m-wide otter trawl net or cast net. Fish samples were collected monthly from October 2010 to September 2011 at 11 sites: site R2, situated near the coastal mudflat about $2 \mathrm{~km}$ offshore from the mouth of the Sangga Besar River; sites R3 to R6 (distance from R2: ca. 4 to $11 \mathrm{~km}$ ) located along the Sangga Besar River, the widest river in the estuarine system; site $\mathrm{S} 1$ (ca. $6 \mathrm{~km}$ ) on the Selinsing River where it converges with the Sangga Besar River at the fishing village of Kuala Sepetang; and sites $\mathrm{C} 1$ to $\mathrm{C} 4$ (ca. 11 to $16 \mathrm{~km}$ ) located in a creek area. The monthly collections across the sampling sites obtained a total of 1,339 specimens of Scatophagus argus (13.0-182.0 mm total length) (Fig. 2). Among these specimens, 132 specimens were used for stable isotope analysis. The total length (TL, $\mathrm{mm}$ ) and body weight (BW, g) of all specimens were measured before the specific analyses.

\section{Stable isotope analysis}

The 132 specimens above used for stable carbon and nitrogen isotope analysis were frozen immediately after collection. The frozen specimens were thawed and rinsed with distilled water before muscle tissues on the left dorsal side of the body were filleted and then dried in an oven at $60^{\circ} \mathrm{C}$ for $24-48 \mathrm{~h}$. The tissues were then ground to a fine powder with a mortar and pestle. Fish white-muscle tissue was used for isotope analysis due to its slow turnover rate, which could reflect the isotopic composition of food assimilated by the fish over several weeks to months (Herzka 2005). To eliminate the effect of lipids on the stable carbon isotope measurements, powdered samples were defatted by adding 2:1 chloroform-methanol solution ( $\mathrm{v} / \mathrm{v})$ and then centrifuged. The defatted samples were oven-dried, and then an aliquot of each sample $(\sim 0.8$ $\mathrm{mg}$ ) was put in a tin container for isotope analyses. The carbon and nitrogen isotope ratios $\left(\delta^{13} \mathrm{C}\right.$ and $\left.\delta^{15} \mathrm{~N}\right)$ were determined using a mass spectrometer (DeltaPlus, Thermo Finnigan). Carbon and nitrogen contents of the samples were also determined with an elemental analyzer (Flash EA1112, Thermo Finnigan). The standard reference materials for carbon and nitrogen in the stable isotope analysis were Vienna PeeDee Belemnite (VPDB) and $\mathrm{N}_{2}$ in atmospheric air, respectively. Results were expressed in standard $\delta$ notation, and values were determined based on the following equations:

$$
\begin{aligned}
& \delta^{13} \mathrm{C}, \%=\left[\left({ }^{13} \mathrm{C} /{ }^{12} \mathrm{C}\right)_{\text {sample }} /\left({ }^{13} \mathrm{C} /{ }^{12} \mathrm{C}\right)_{\text {standard, }, \mathrm{VPB}}-1\right] \times 10^{3} \\
& \delta^{15} \mathrm{~N}, \% 0=\left[\left({ }^{15} \mathrm{~N} /{ }^{14} \mathrm{~N}\right)_{\text {sample }} /\left({ }^{15} \mathrm{~N} /{ }^{14} \mathrm{~N}\right)_{\text {standard, air }}-1\right] \times 10^{3}
\end{aligned}
$$

Instrument precision was $0.2 \%$ for the measurements of both $\delta^{13} \mathrm{C}$ and $\delta^{15} \mathrm{~N}$.

\section{Results}

Figure 3 shows dual plots of the organic carbon and nitrogen isotopic compositions of the sampled Scatophagus argus together with their potential food items in the MMFR (i.e., phytoplankton from coastal offshore waters, microphytobenthos from sites R2, R5 and $\mathrm{C} 3$, mangrove leaves inside the estuary) (data from Okamura et al. 2012). The S. argus had an overall mean \pm standard deviation (SD) of $\delta^{13} \mathrm{C}$ and $\delta^{15} \mathrm{~N}$ values of $-25.0 \pm 2.5 \%$ and $11.6 \pm 1.4 \%$, respectively, with the

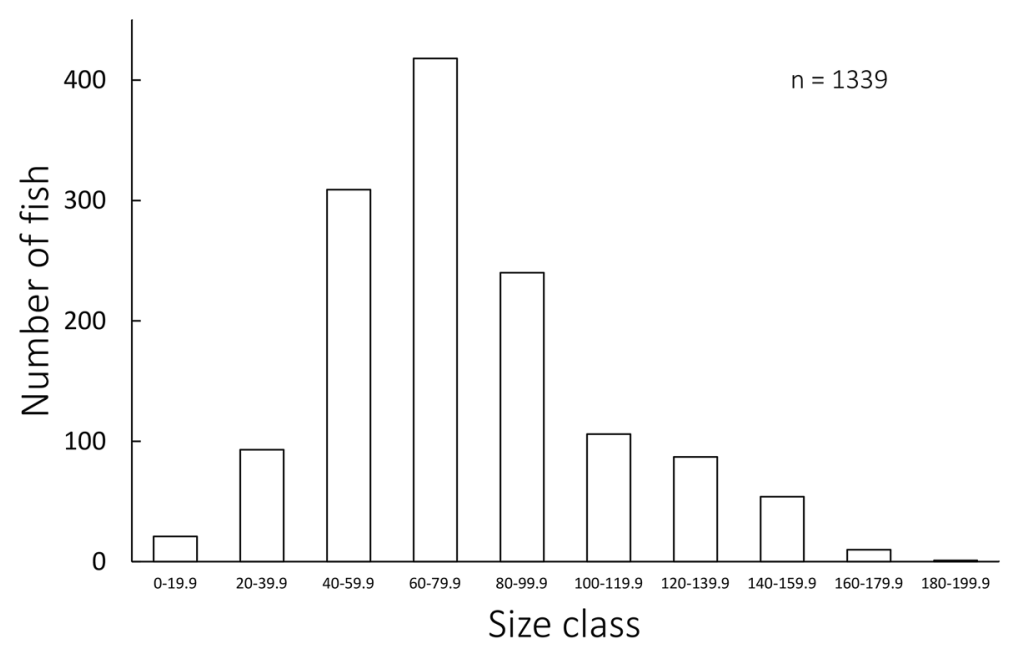

Fig. 2. Size frequency distribution of Scatophagus argus collected from the MMFR 
values ranging widely depending on the sampling site. The differences observed in the $\delta^{13} \mathrm{C}$ values between the sampling sites are considered to reflect the different carbon sources inherent in the food items available to the fish at each site. Fish sampled from the coastal mudflat area (R2) had the most enriched mean values of $\delta^{13} \mathrm{C}$ $(-19.4 \pm 1.0 \%$ ) (Fig. 3). In contrast, along the river and in the creek areas (S1/R3-R6 and C1-C4), the $\delta^{13} \mathrm{C}$ values of S. argus (ca. -19 to $-27 \%$ ) were between the range covered by the $\delta^{13} \mathrm{C}$ values of coastal phytoplankton, microphytobenthos, and mangrove leaves (ca. -17 to $-30 \%$ ), and fish sampled from an upstream creek area (C4) had the most depleted mean value of $\delta^{13} \mathrm{C}(-27.4 \pm$ 2.0\%) (Fig. 3).

The $\delta^{13} \mathrm{C}$ values of Scatophagus argus collected from the coastal mudflat area at the river mouth (R2) showed the highest mean value $(-19.4 \pm 1.0 \%)$, and the values tended to decrease with increasing distance of the collection sites from the river mouth toward the inner creek areas along the Selinsing River ( $\mathrm{S} 1$ with a value of $-23.0 \pm 3.0 \%$, C1-C4 and SLG2 with ca. -25 to $-27 \%$ ) (Figs. 1 and 4). Similarly, the $\delta^{13} \mathrm{C}$ values of fish collected along the Sangga Besar River showed a decreasing trend with increasing distance of the collection sites from the river mouth (R3 with a value of $-24.1 \pm 1.6 \%$, R4-R6 with ca. -24 to $-25 \%$ ) (Figs. 1 and 4 ). The overall relationship between the $\delta^{13} \mathrm{C}$ values of fish collected from each sampling site $(\mathrm{C})$ and the distances from the

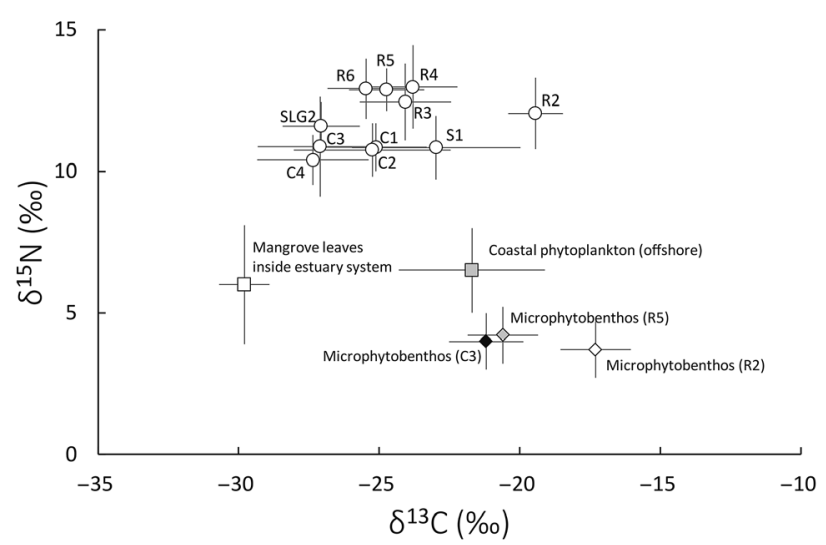

Fig. 3. Dual plots of stable carbon and nitrogen isotope ratios of Scatophagus argus and its potential prey items (data from Okamura et al. 2012) collected from the MMFR

Open circle: S. argus (with superscripts indicating sample collection sites), Open square: mangrove leaves inside estuary systems, grey square: coastal phytoplankton collected offshore, closed diamond: microphytobenthos collected from site C3, grey diamond: microphytobenthos collected from site R5, open diamond: microphytobenthos collected at the river mouth (site R2), error bars: standard deviations river mouth for each site (D) was significantly corelated with the following formula: $\mathrm{C}=-0.39 \mathrm{D}-21.12\left(\mathrm{R}^{2}=\right.$ 0.37, $\mathrm{n}=132, P<0.01$ ) (Fig. 4).

In relation to size, the $\delta^{13} \mathrm{C}$ values of $S$. argus were relatively depleted (ca. $-26 \%$ ) in specimens sized between 20.0 and $100.0 \mathrm{~mm}$ TL, while the values were enriched to $-22 \%$ in the smallest size class $(<20.0 \mathrm{~mm}$ TL) and tended to increase in fish $>100 \mathrm{~mm}$ TL with increasing fish size, measuring up to $-20 \%$ in fish $>160$ mm TL (Fig. 5). In the three smallest specimens (13.0$15.0 \mathrm{~mm} \mathrm{TL}$ ) analyzed here, the characteristics of the tholichthys larval stage (i.e., protective sheath-like bony plates covering the head) still remained.

\section{Discussion}

Chew et al. (2012) estimated that $8-44 \%$ of nutrition for juvenile fish in the Matang Mangrove Forest Reserve (MMFR) is derived from mangrove sources, with mangrove-derived carbon occurring in the upper estuary becoming more important. In the present study, the $\delta^{15} \mathrm{~N}$ values of Scatophagus argus collected from the river and creek areas (S1/R2-R6, SLG2 and C1-C4) were more enriched $(5-7 \%$ ) than those of phytoplankton in coastal waters, microphytobenthos (R2, R5 and C3), and mangrove leaves in the estuary (Fig. 3). These values demonstrate that $S$. argus is a secondary consumer by adapting the generally accepted trophic enrichment

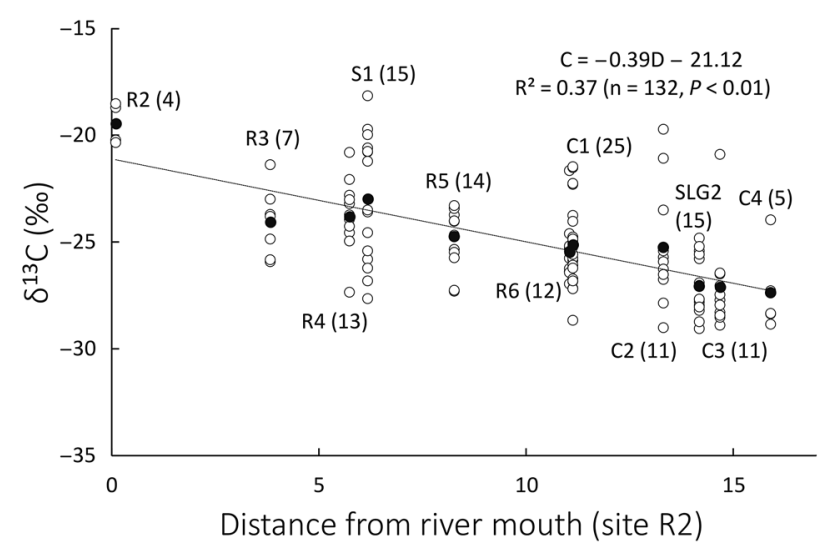

Fig. 4. Relationship between values (\%) of stable carbon isotope ratios in Scatophagus argus from each collection site and distances from the river mouth (site R2) to each collection site in the MMFR, Malaysia

Open circle: data plots of actual values, closed circle: mean values of stable carbon isotope ratios at each collection site, number in parentheses: number of analyzed samples at each collection site. A formula was regressed with the data plots of actual values. 


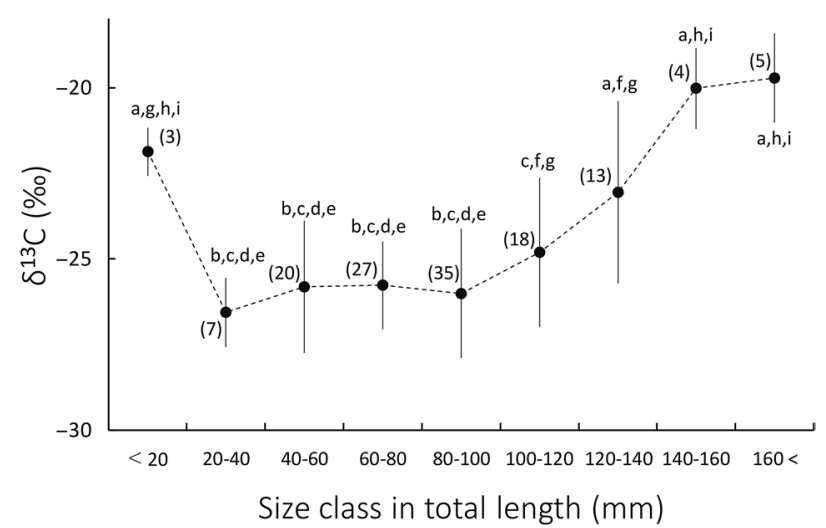

Fig. 5. Values (\%o) of stable carbon isotope ratio for different size classes (total length, $\mathrm{mm}$ ) of Scatophagus argus collected in the MMFR

Vertical bar: standard deviation, number in parentheses: number of analyzed samples in each size class. Different characters indicate significant differences.

values (2-4\%o for $\left.\delta^{15} \mathrm{~N}\right)$ (Sugisaki et al. 2013). Although organisms as primary consumers were not analyzed in the present study, $S$. argus is known to be an omnivore (Gandhi 2002) feeding on various food items including such primary consumers as zooplankton, protozoan, and mysids (Thimdee et al. 2004, Wongchinawit \& Paphavasit 2009, Gupta 2016), thus indicating the species niche as a secondary consumer. In addition to the observations above, the $\delta^{13} \mathrm{C}$ values of $S$. argus observed here covered a wide range, with higher $\delta^{13} \mathrm{C}$ values (ca. $-19 \%$ ) found in fish collected from the river mouth area (R2) to lower $\delta^{13} \mathrm{C}$ values in fish from the inner mangrove estuary $(<-27 \%$ at $\mathrm{C} 4)$ (Fig. 3). Moreover, the trend in changes of $\delta^{13} \mathrm{C}$ values by distances of the fish collection sites from the river mouth (Fig. 4) strongly suggests that the $\delta^{13} \mathrm{C}$ values of fish reflected the $\delta^{13} \mathrm{C}$ values of the food items occurring at each collection site, and this consideration is also explainable by the trend of $\delta^{13} \mathrm{C}$ values of potential prey items being higher in coastal/ river mouth areas than in inner estuary areas (Figs. 1 and 3). In addition, Tanaka et al. (2011) reported that the $\delta^{13} \mathrm{C}$ values of mysids (Mesopodopsis, Acanthomysis, and Rhopalophthalmus) and decapods (Acetes spp.) as primary consumers and food items of $S$. argus were higher in the river mouth area, and that the values became lower towards the upstream area of the estuary system in the MMFR. Furthermore, Okamura et al. (2010) revealed that the $\delta^{13} \mathrm{C}$ values of surface sediments, which are the traces of potential food organisms for S. argus, showed a similar trend in the MMFR. This information also suggests that the $\delta^{13} \mathrm{C}$ values of the fish body are dependent on the $\delta^{13} \mathrm{C}$ values of the food items by collection sites with different carbon source origins.

Relatively higher $\delta^{13} \mathrm{C}$ values in fish $<20 \mathrm{~mm}$ TL and $>100 \mathrm{~mm} \mathrm{TL}$, and lower values in fish of $20-100 \mathrm{~mm}$ TL were observed (Fig. 5). Given that the mature specimens occurred offshore (Gandhi et al. 2014) and were scarcely present in the MMFR (S. Morioka, unpubl. data), S. argus is considered to breed offshore. Planktonic larvae of $S$. argus reportedly feed on phytoplankton/ zooplankton in surface water (Boonruang et al. 1994, Musikasung et al. 2006, Wongchinawit \& Paphavasit 2009), and subsequently the feeding area shifts from surface water to the bottom area during development at the juvenile/adult stages (Gandhi 2002, Gupta 2016). In the present study, the three smallest specimens of 13.0$15.0 \mathrm{~mm}$ TL still had the characteristics of the tholichthys stage, that is, pelagic/planktonic larvae with a size range of 6-12 mm TL (Barry \& Fast 1992). Given this context, the higher $\delta^{13} \mathrm{C}$ values in fish $<20 \mathrm{~mm}$ TL (Fig. 5) are thus considered a signature of such prey as coastal phytoplankton having higher $\delta^{13} \mathrm{C}$ values observed in this study (Fig. 3). Since $S$. argus is consistently a bottom omnivorous feeder after reaching the juvenile stage (Sivan \& Radhakrishnan 2011), lower $\delta^{13} \mathrm{C}$ values in fish of 20-40 mm TL (Fig. 5) are considered to be caused by the shift in feeding habitats from offshore surface water to bottom areas in the estuary system as part of the ontogenetic development of fish, and subsequent low $\delta^{13} \mathrm{C}$ values in fish of 20-100 mm TL reflect their food items in the inner estuary having lower $\delta^{13} \mathrm{C}$ values [Fig. 3 and Okamura et al. (2010)]. Moreover, higher $\delta^{13} \mathrm{C}$ values are observed in fish $>100 \mathrm{~mm}$ TL (Fig. 5), although the trend is slower than that of the decreasing trend in fish of 20-40 mm TL, suggesting that the habitat shift of fish migrating from the inner estuary towards the river mouth area as being due to fish growth. The turnover of isotopic compositions is known to be more rapid in younger (smaller-size) specimens and more extended in larger ones (Hoffman et al. 2007, 2011, Xia et al. 2013). The slower increasing trend in $\delta^{13} \mathrm{C}$ values in larger fish $>100$ $\mathrm{mm}$ TL than the decreasing trend in fish $<40 \mathrm{~mm}$ TL (Fig. 5) is thus likely due to the slower turnover of isotopic compositions in larger fish during the habitat shift from the inner estuary to the river mouth area.

\section{Conclusion}

The sizes at sexual maturity of Scatophagus argus were reported to be $>140 \mathrm{~mm}$ TL for females and $>120$ $\mathrm{mm}$ TL for males, and mature specimens occurred offshore (Gandhi et al. 2014). However, the limited portions of specimens reaching those sizes $[4.9 \%(65$ fish) $>140 \mathrm{~mm}$ TL as female maturation size and $11.4 \%$ (152 fish) $>120 \mathrm{~mm}$ TL as male maturation size] were observed in the MMFR (Fig. 2). In addition, the larvae of 
many euryhaline tropical fishes are known to move or be carried into the mangrove estuary of the MMFR from offshore (Gillanders et al. 2003, Blaber 2007, Sarpedonti $\&$ Chong 2008). Hence, the above information and findings obtained in the present study suggest the ontogenetic migration of $S$. argus; that is, the species breeds in offshore waters, the planktonic larvae (tholichthys larval stage) are considered to subsequently migrate into the mangrove estuary from outer coastal areas (probably carried by the tidal current), grow in the estuary as a nursery grounds, and eventually migrate back to the offshore water for breeding after reaching maturation size. To confirm this migratory pattern of the species, analysis of gonadal development of $S$. argus is to be made.

\section{Acknowledgments}

The authors gratefully acknowledge the logistical support provided by the Fisheries Research Institute, Penang, Malaysia. The present study was funded by the Japan International Research Center for Agricultural Sciences (JIRCAS), and in part by Grants-in-Aid for Scientific Research from the Japan Society for the Promotion of Science (No. 22405030).

\section{References}

Barry, T. P. \& Fast, A. W. (1992) Biology of spotted scat (Scatophagus argus) in the Philippines. Asian Fish. Sci., 5,163-179.

Blaber, S. J. M. (2007) Mangroves and fishes: issues of diversity, dependence, and dogma. Bull. Mar. Sci., 80, 457-472.

Boonruang, P. et al. (1994) The community structure of fish and their relation to food items in the mangrove area, Phangnga Bay. In Proceeding of the Seminar on Fisheries 1994, Department of Fisheries, Ministry of Agriculture and Cooperatives, Bangkok, 230-248.

Chew, L. L. et al. (2012) Phytoplankton fuel the energy flow from zooplankton to small nekton in turbid mangrove waters. Mar. Ecol. Prog. Ser., 469, 7-24.

Gandhi, V. (2002) Studies on the food and feeding habits of cultivable butterfish Scatophagus argus (Cuv. and Val.). J. Mar. Biol. Ass. India, 44, 115-121.

Gandhi, V. et al. (2014) Reproductive biology of the spotted scat Scatophagus argus (Linnaeus, 1766) from Mandapam waters, south-east coast of India. Indian. J. Fish., 61, 55-59.

Gillanders, B. M. et al. (2003) Evidence of connectivity between juvenile and adult habitats for mobile marine fauna: an important component of nurseries. Mar. Ecol. Prog. Ser., 247, 281-295.

Gupta, S. (2016) An overview on morphology, biology, and culture of Spotted Scat Scatophagus argus (Linnaeus 1766). Rev. Fish. Sci. Aquacul., 24, 203-212.

Herzka, S. Z. (2005) Assessing connectivity of estuarine fishes based on stable isotope ratio analysis. Estuar. Coast. Shelf. Sci., 64, 58-69.

Hobson, K. A. (1999) Tracing origins and migration of wildlife using stable isotopes: a review. Oecologia, 120, 314-326.

Hoffman, J. C. et al. (2007) Tracking nursery habitat use by young American shad in the York River estuary, Virginia using stable isotopes. Trans. Am. Fish. Soc., 136, 1285-1297.

Hoffman, J. C. et al. (2011) Rapid stable isotope turnover of larval fish in a Lake Superior coastal wetland: implications for diet and life history studies. Aquat. Ecosystem Health \& Mgmt., 14, 403-413.

Hui, A. T. Y. (2009) The structure and trophodynamics of the fish community in estuaries of Matang mangrove forest reserve, Peninsula Malaysia. Master's dissertation, Institute of Biological Science, Faculty of Science, University of Malaya, Kuala Lumpur.

Maruyama, A. et al. (2001) Stable nitrogen and carbon isotope ratios as migration tracers of landlocked goby, Rhinogobius sp. (the orange form), in the Lake Biwa water system. Ecol. Res., 16, 697-703.

Musikasung, W. et al. (2006) Stomach content and ecological feature of Scatophagus argus (Linnaeus) in Songkhla Lake. Technical Paper No. 47, Coastal Aquaculture Research Institute, Coastal Fisheries Research and Development Bureau, Bangkok.

Okamura, K. et al. (2010) Spring tide hypoxia with relation to chemical properties of the sediments in the Matang mangrove estuary, Malaysia. JARQ, 44, 325-333.

Okamura, K. et al. (2012) Chemical properties of the surface sediments with relation to the hypoxia in the Matang Mangrove Estuary, Malaysia. JIRCAS Working Report, 75, Japan International Research Center for Agricultural Sciences, Tsukuba, 7-14.

Sarpedonti, V. \& Chong, V. C. (2008) Abundance and distribution of Stolephorus baganensis (Hardenberg 1933) and Thryssa kammalensis (Bleeker 1849) larvae in relation to ontogeny and environmental factors in a Malaysian estuary. Trop. Zool., 21, 195-208.

Sivan, G. \& Radhakrishnan, C. K. (2011) Food, Feeding Habits and Biochemical Composition of Scatophagus argus. Turkish J. Fish. Aquat. Sci., 11, 603-608.

Sugisaki, H. et al. (2013) A new aspect on food web analyses using a nitrogen and carbon isotope map - guidance for interpretations of values and estimation model for stable isotope values of primary producers of food web. J. Fish. Tech., 6, 57-68. [In Japanese].

Suzuki, K. W. et al. (2008) Distinctive stable isotope ratios in important zooplankton species in relation to estuarine salinity gradients: potential tracer of fish migration. Estuar. Coast. Shelf Sci., 78, 541-550.

Tanaka, K. et al. (2011) Stable isotope analysis reveals ontogenetic migration and the importance of a large mangrove estuary as a feeding ground for juvenile John's snapper Lutjanus johnii. Fish. Sci., 77, 809-816.

Thimdee, W. et al. (2004) Analysis of primary food sources and trophic relationships of aquatic animals in a mangrovefringed estuary, Khung Krabaen Bay (Thailand) using dual stable isotope techniques. Wetlands Ecol. Mgmt., 12, 135-144.

Wongchinawit, S. \& Paphavasit, N. (2009) Ontogenetic niche shift in the spotted scat, Scatophagus argus, in Pak 
Phanang Estuary, Nakhon Si Thammarat Province, Thailand. Nat. Hist. J. Chulalongkorn Univ., 9, 143-169.

Xia, B. et al. (2013) Carbon stable isotope turnover and fractionation in grass carp Ctenopharyngodon idella tissues. Aquat. Biol., 19, 207-216.
Yamamoto, T. et al (2010) Preliminary study on growth of juvenile orange-spotted grouper Epinephelus coioides collected off northwest peninsular Malaysia. Malaysian Fish. J., 9, 57-70. 